\title{
Accuracy Evaluation of Advanced Geological Prediction Based on Improved AHP and GPR
}

\author{
Lifei Zheng $\mathbb{C}^{1},{ }^{1}$ Xiaoqing Li $\mathbb{D}^{1},{ }^{1}$ Zitong Liu, ${ }^{2}$ Dan Huang $\mathbb{D},{ }^{1}$ and Zonglei Tang ${ }^{1}$ \\ ${ }^{1}$ School of Civil Engineering and Mechanics, Huazhong University of Science and Technology, Wuhan 430074, China \\ ${ }^{2}$ Central South Architectural Design Institute Co., Ltd., Wuhan 430071, China \\ Correspondence should be addressed to Xiaoqing Li; xql@mail.hust.edu.cn
}

Received 16 May 2020; Revised 6 August 2020; Accepted 14 August 2020; Published 2 September 2020

Academic Editor: Rafał Stanisławski

Copyright (c) 2020 Lifei Zheng et al. This is an open access article distributed under the Creative Commons Attribution License, which permits unrestricted use, distribution, and reproduction in any medium, provided the original work is properly cited.

Ground penetrating radar (GPR) is widely used in advanced geological prediction. It is necessary to choose a scientific and effective evaluation method to give a reasonable evaluation of the accuracy of prediction. In this paper, a method based on improved analytic hierarchy process (AHP) and GPR is proposed to evaluate the accuracy of advanced geological prediction. Based on the analysis and induction of the factors that affect the accuracy of GPR prediction, an improved AHP is proposed, in which a new measure of "numerical weight" is added and the principle of maximum membership degree is integrated, and an improved AHP model is established for GPR prediction accuracy classification and evaluation. The engineering application of Xiaobeishan Tunnel of Jie-Hui Highway is taken as a case study, and it is proved that the evaluation indices are easy to obtain and the evaluation results are accurate and reliable. The improved AHP-GPR method can be further used for other tunnel engineering.

\section{Introduction}

In the construction of tunnels, geological disasters such as collapse, fault, karst, underground river, and permafrost are often encountered [1-4]. However, it is difficult for geological surveys to meet actual needs in terms of accuracy and reliability. It is not enough to rely on preconstruction surveys to prevent adverse geological conditions during construction. If we can find out the surrounding rock condition of the tunnel face in time and make a correct judgment on the shape and scale of the adverse structure, we can arrange the support in time and correct the construction plan, so as to avoid the dangerous situation [5-7].

Advanced geological prediction can provide a scientific basis for prevention of geological disasters and effective arrangement of construction progress. Ground penetrating radar (GPR) technology has been widely recognized by peers because of its high resolution, intuitive results, and fast scanning speed [8-12]. However, the prediction results of GPR are interfered by many factors, such as error of original signal acquisition, human operation error, image interpretation, and understanding of the scene, all of which are uncertain [13-16].
At present, GPR is widely used in mining engineering $[17,18]$, water conservancy and hydropower engineering [19-21], road engineering [22-24], tunnel engineering [25-27], etc. However, there are relatively few studies on the accuracy of GPR prediction. Some scholars have explored the accuracy of advanced prediction. Ren et al. used a combination of long- and short-distance advanced geological prediction methods to modify the factors affecting the classification of tunnel surrounding rock grades and carried out dynamic division to improve the accuracy of tunnel advanced geological prediction [28]. Li et al. extracted relevant geological parameters and geophysical exploration result parameters for several common unfavorable geological conditions and used the fuzzy neural network method to realize the comprehensive prediction of common unfavorable geological conditions in tunnels [29]. Ge et al. used a fuzzy mathematical model to evaluate and classify the risk of the tunnel and optimized the prediction scheme and process of the comprehensive geological prediction to improve the positioning accuracy of the karst water [30]. Lu used the fuzzy comprehensive evaluation method to 
comprehensively evaluate the stability of the surrounding rock of the collapsed section of the tunnel and obtained a revised evaluation system of the stability of the surrounding rock of the tunnel. The evaluation results are consistent with the actual situation [31]. Li proposed a comprehensive geological forecasting scheme based on a combination of geological analysis, hazard classification, comprehensive classification prediction, and construction geological disaster warning, and it was successfully applied in Qiyueshan Tunnel [32]. Shi et al. proposed an advanced optimization classification method to accurately predict the surrounding rock classification based on FAHP and TSP [33].

Recent studies show that the application of fuzzy comprehensive evaluation in tunnel engineering is not mature. Although many scholars have obtained effective evaluation results, there are some problems that cannot be ignored in the evaluation process; for example, (1) the selection of evaluation factors is too simple to comprehensively include the actual situation of the evaluation object; (2) the evaluation method is divorced from reality and is too theoretical to be fed back into actual operation for guidance; (3) the weight of evaluation factors is too subjective, and expert experience accounts for a large proportion; (4) another problem is the traditional fuzzy comprehensive evaluation method for multiobject evaluation-the evaluation factor lower resolution.

Aiming at the above problems, this paper will use the analytic hierarchy process (AHP) with a more reasonable weight system as the main evaluation method. At the same time, the advantages of the fuzzy comprehensive evaluation method will be incorporated into it, and it will become an improved AHP to evaluate the accuracy of the advanced prediction results of the GPR. The method has good applicability and can be extended to other projects, such as tunnel, roadway, and diversion tunnel.

\section{Effect Factor Analysis of the Accuracy of Advanced Geological Prediction Based on GPR}

2.1. The Principle of GPR. GPR is a method for determining the distribution of underground media by emitting highfrequency electromagnetic waves [34], as shown in Figure 1. The transmitting antenna and the receiving antenna move synchronously along the survey line. The transmitting antenna sends out a high-frequency electromagnetic wave in the form of broadband pulse, and the high-frequency electromagnetic wave is absorbed by the receiving antenna after reflection or transmission. The time required for this process is $t$ :

$$
t=\frac{\sqrt{4 z^{2}+x^{2}}}{v},
$$

where $z$ is the reflection interface depth $(\mathrm{m}), v$ is the propagation velocity of the electromagnetic wave in the medium $(\mathrm{m} / \mathrm{s})$, and $x$ is the distance between the transmitting antenna and the receiving antenna $(\mathrm{m})$.

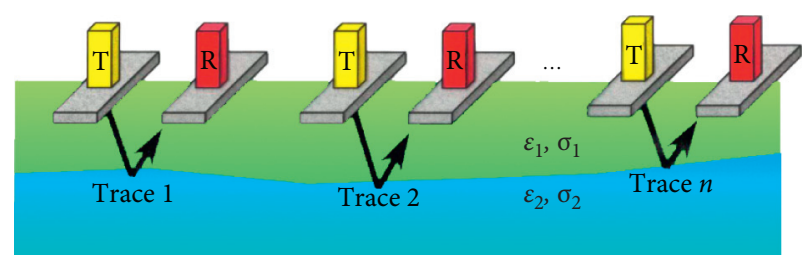

FIGURE 1: The principle of GPR.

When the conductivity of the medium is not considered, the wave velocity of the electromagnetic wave in the medium is $v$ :

$$
v \approx \frac{c}{\sqrt{\varepsilon}}
$$

where $c$ is the speed of light in vacuum $(\mathrm{m} / \mathrm{s})$ and $\varepsilon$ is the relative dielectric constant of underground medium.

When an electromagnetic wave passes through two different media, it will reflect. The larger the reflection coefficient, the larger the amplitude of the reflected signal. The reflection coefficient $R$ can be expressed as

$$
R=\frac{\sqrt{\varepsilon_{1}}-\sqrt{\varepsilon_{2}}}{\sqrt{\varepsilon_{1}}+\sqrt{\varepsilon_{2}}}
$$

where the subscripts 1 and 2 represent the two different media.

It can be seen from formula (3) that (when the electromagnetic wave penetrates different media) the greater the dielectric constant difference, the greater the reflection coefficient and the greater the energy of the reflected wave, so that this part can be clearly displayed in the radar image. This change in the reflected waveform due to the difference in dielectric constant becomes the primary basis for judging the lithology in front of the tunnel face.

2.2. Analysis of Evaluation Factor. In combination with the actual operation of the project, the factors affecting the accuracy of advanced geological prediction are summarized here.

2.2.1. Raw Data Collection. The collection of raw data is the link with the most errors. The factors that cause errors include antenna center frequency selection, sampling rate selection, measuring point distance, antenna spacing selection, time window selection, etc. These factors can be summarized as measurement parameter selection. There are line layout, construction site interference, and other factors, which can be summarized as signal coverage.

2.2.2. Human Factors. The human factors mainly include the understanding of the tunnel face information, the understanding of the overall tunnel information, the interpretation of radar image data, and software processing including digital filtering, offset processing, and enhancement processing. 
2.2.3. Prediction of Distance. GPR detection range can reach up to $50 \mathrm{~m}$. The results beyond $40 \mathrm{~m}$ will often cause misjudgment by technicians and are generally not used as a reference. The detection signal within $30 \mathrm{~m}$ has better definition and higher resolution, and the detection result has a higher reference value. But at the same time, the detection signal will also be interfered by other factors. We cannot simply assume that the shorter the detection distance, the higher the accuracy.

Due to the complexity of factors affecting the accuracy of GPR prediction, in order to improve the efficiency and rationality of evaluation, the authors classify and grade the summarized evaluation factors according to the AHP method. The hierarchical structure system is shown in Figure 2.

\section{Improved AHP Evaluation Model}

Advanced prediction of GPR is a complex system problem. It is impossible to simply use classification or clustering methods to assess its accuracy, and it is unreasonable to set an accuracy coefficient simply. Because geological differences, man-made differences, and even some unexpected factors are integrated in the results, there are differences in predictions. Therefore, in any advanced prediction work, technicians will always pay attention to the various geological conditions on the spot and then combine the predictions of the instruments to make a comprehensive geological evaluation. Whether the evaluation is reasonable or not depends on whether all the factors that affect the accuracy of the prediction are fully considered. So we establish the improved AHP evaluation model to evaluate the accuracy of the prediction.

First proposed by Saaty and Tran [35-37], the analytic hierarchy process (AHP) is suitable for dealing with complex systems related to making a choice from several alternatives and provides a comparison of the considered options. According to the analysis results of the above chapters, there are many factors that affect the accuracy. When there are too many evaluation factors, the amount of calculation for hierarchical ranking is too large. Based on the advantages and disadvantages of the fuzzy comprehensive evaluation and the AHP, the authors improved the traditional AHP to solve practical problems, as follows:

(1) When using the AHP to determine the comprehensive weight, a new measure called "numerical weight" is added to weight the commonly used values of the parameters of some factors. Combining the numerical weight with the characteristic weight in the traditional AHP method, a more scientific comprehensive weight is obtained.

(2) The method of fuzzy comprehensive evaluation using the membership function to calculate the fuzzy matrix for final evaluation is integrated into the AHP, and the final result is evaluated according to the "maximum degree of membership."

\subsection{Determination of Weight}

3.1.1. Determination of Feature Weight. Feature weight can be derived from analytic hierarchy process. A judgment matrix can be obtained by using the 1-9 scale method suggested by T. L. Saaty (1990). The feature vector and the maximum eigenvalues of the matrix can be expressed in the following forms:

$$
\begin{array}{r}
s_{i}=\frac{1}{n} \sqrt[n]{\prod_{j=1}^{n} a_{i j}} \\
\lambda_{\max }=\frac{1}{n} \sum_{i=1}^{n} \frac{(A S)_{i}}{a_{i}},
\end{array}
$$

where $A$ is the judgment matrix; $a_{i}$ is the weight of evaluation index; $S=\left(a_{1}, a_{2}, \ldots, a_{n}\right)$ is the feature vector of $A$; $\lambda_{\max }$ is the maximum eigenvalues of $A ; n$ is the quantity of evaluation indices; $i=1,2, \ldots, n$; and $j=1,2, \ldots, n$.

Take the ratio of $\mathrm{CI}$ and $\mathrm{RI}$ as the discriminate of consistency check, and the ratio of $\mathrm{CI}$ and RI can be expressed in the following form:

$$
\mathrm{CR}=\frac{\mathrm{CI}}{\mathrm{RI}}=\frac{\left(\lambda_{\max }-n\right) /(n-1)}{\mathrm{RI}},
$$

where $\mathrm{CI}$ is the consistency indicator; RI is the average random consistency indicator; $C R$ is the random coincidence coefficient; and $\mathrm{CR}<0.1$ indicates that the matrix satisfies the requirement of consistency check.

3.1.2. Determination of Numerical Weight. According to the abovementioned evaluation factors, we can see that some factors such as center frequency, point distance, time window, antenna distance, and prediction distance have specific measured values. For a specific factor, different values will obviously have different degrees of impact on the final accuracy of GPR prediction. Therefore, we set a concept of numerical weight: $\beta=\left(\beta_{1}, \beta_{2}, \ldots, \beta_{n}\right)$, with the calculation formula

$$
\beta_{j}=\frac{x_{j} / \sum_{i=1}^{4} a_{i j}}{\sum_{j=1}^{n}\left(x_{j} / \sum_{i=1}^{4} a_{i j}\right)},
$$

where $x_{j}$ is the actual value taken in a certain detection of the $j^{\text {th }}$ factor; $\beta_{j}$ is the numerical weight of the $j^{\text {th }}$ factor; and $a_{i j}$ is the standard value of level $i$ of the $j^{\text {th }}$ factor.

3.1.3. Determination of Comprehensive Weight. The final comprehensive weight is obtained from the algebraic product of the feature weight $\alpha$ and the numerical weight $\beta$, which is normalized into a new vector $W=\left(w_{1}, w_{2}, \ldots, w_{n}\right)$ as the comprehensive weight. The calculation formula is

$$
w_{j}=\frac{\left(\alpha_{j} \beta_{j}\right)}{\sum_{j=1}^{n}\left(\alpha_{j} \beta_{j}\right)},
$$




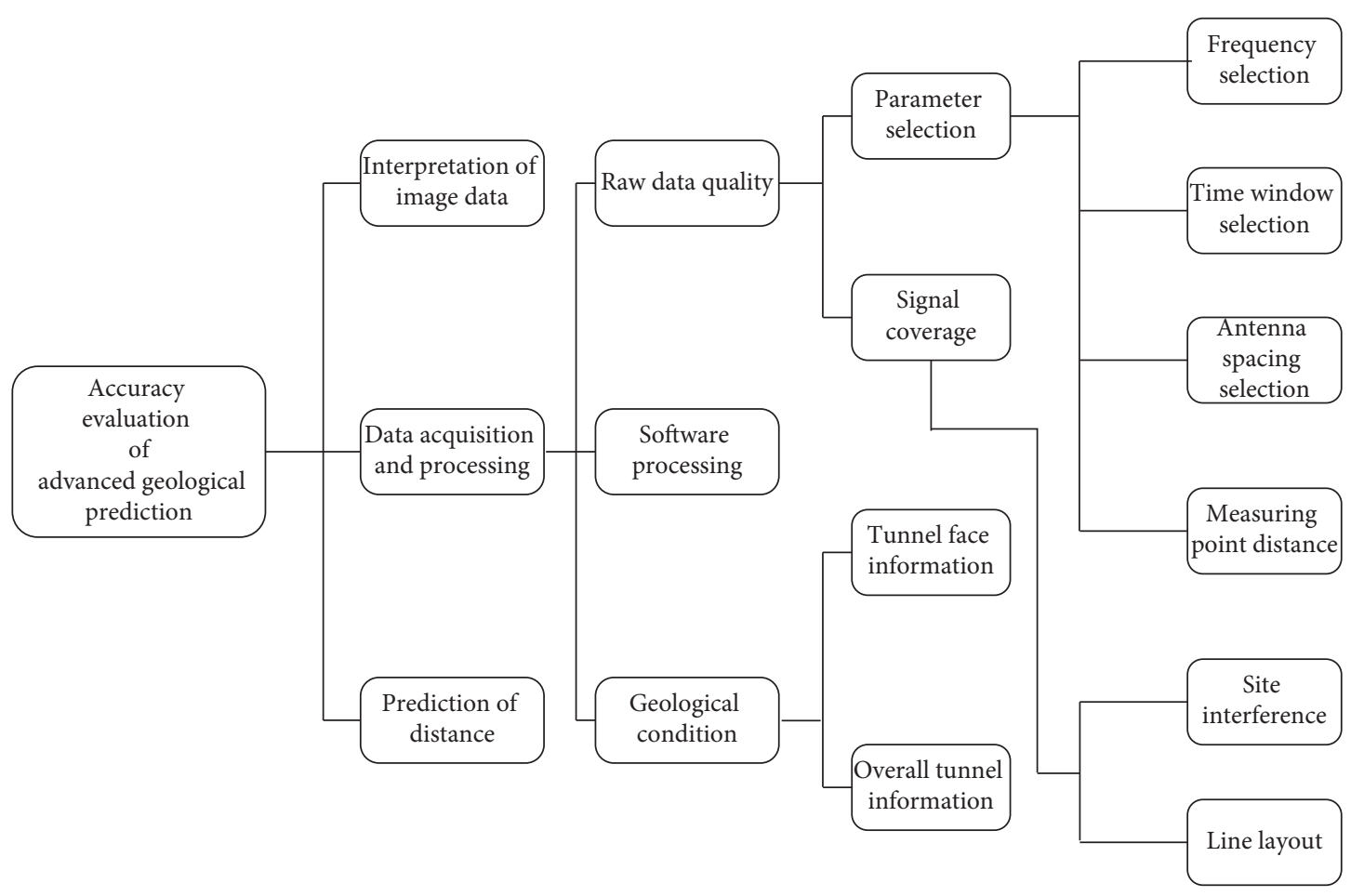

FIGURE 2: Hierarchical structure system of evaluation factors.

where $w_{j}$ is the comprehensive weight of the $j^{\text {th }}$ factor, $\beta_{j}$ is the numerical weight of the $j^{\text {th }}$ factor, and $\alpha_{j}$ is the feature weight of the $j^{\text {th }}$ factor.

\subsection{Determination of the Factor Standard Value and Membership Function}

3.2.1. The Factor Standard Value. For the evaluation of field interference, tunnel geological conditions, software processing, image data interpretation, and other factors, as they are more abstract, the standard value is taken as 1, the actual value is the dimensionless relative value of the standard value, and the final result is shown in Table 1. The range of standard values in the table is obtained after repeated verification by experienced technicians through expert questionnaires. The value of evaluation factor is based on the following formula [38]:

$$
V_{F}=\frac{V_{S}-\left|V_{S}-V_{M}\right|}{V_{S}}
$$

where $V_{F}$ is the evaluation factor value, $V_{S}$ is the standard value, and $V_{M}$ is the measured value.

\subsection{Establishment and Identification of Model}

3.3.1. Determination of Membership Function. According to the characteristics of the evaluation factors in this paper, the ridge distribution is more suitable for the membership function [39]. In order to achieve the effect that the larger the value of $A(x)$, the higher the membership, the conventional ridge membership function is modified. Set the original standard value as $a_{0}$. The four-level standard values greater than $\mathrm{a}_{0}$ are $a_{1}, a_{2}, a_{3}, a_{4}$ from small to large. The four-level standard values less than $a_{0}$ are $a^{1}, a^{2}, a^{3}, a^{4}$ from large to small. The function graphs are shown in Figure 3.

3.3.2. Selection of Fuzzy Operators. Considering that there are many evaluation factors involved in the evaluation object of this article and the relative importance of each factor is not much different, it is not possible to neglect it, so it is decided to replace the common $(\wedge, \vee)$ operator with an improved fuzzy operator $(\cdot,+)$. This model is called a weighted average model, which has less loss of information and higher resolution. After this calculation, the evaluation factors can compensate each other, improve the sensitivity of the system, and are easy to program.

3.3.3. Establishment of Evaluation Model. According to the summarized hierarchical structure system of evaluation factors, we establish a hierarchical evaluation model as shown in Table 2. In the table, the evaluation factors are evaluated in layers, and the parameters of each factor are marked.

(1) First level comprehensive evaluation matrix and mathematical model: establish a single-factor membership function model, obtain the membership degree $r_{i j}$ of each factor to each level of $a, b, c$, and $d$ 
TABLE 1: Standard value of membership degree of evaluation factor.

\begin{tabular}{|c|c|c|c|c|c|c|}
\hline Items & Factor & $\begin{array}{l}\text { Standard } \\
\text { value }\end{array}$ & $\begin{array}{c}\text { More } \\
\text { accurate }\end{array}$ & Accurate & $\begin{array}{c}\text { Relatively } \\
\text { accurate }\end{array}$ & Inaccurate \\
\hline \multirow{5}{*}{ Raw data collection } & $\begin{array}{l}\text { Frequency selection } \\
\text { Time window selection }\end{array}$ & $\begin{array}{l}100 \mathrm{MHz} \\
500 \mathrm{~ns}\end{array}$ & $\begin{array}{l}0.85 \leq F_{1} \\
0.9 \leq F_{2}\end{array}$ & $\begin{array}{c}0.7 \leq F_{1}<0.85 \\
0.8 \leq F_{2}<0.9\end{array}$ & $\begin{aligned} 0.65 & \leq F_{1}<0.75 \\
0.7 & \leq F_{2}<0.8\end{aligned}$ & $\begin{array}{c}0.4 \leq F_{1}<0.65 \\
0.6 \leq F_{2}<0.7\end{array}$ \\
\hline & $\begin{array}{c}\text { Antenna spacing } \\
\text { selection }\end{array}$ & $1.8 \mathrm{~m}$ & $0.95 \leq F_{3}$ & $0.85 \leq F_{3}<0.95$ & $0.75 \leq F_{3}<0.85$ & $0.65 \leq F_{3}<0.75$ \\
\hline & $\begin{array}{l}\text { Measuring point } \\
\text { distance }\end{array}$ & $0.1 \mathrm{~m}$ & $0.9 \leq F_{4}$ & $0.7 \leq F_{4}<0.9$ & $0.5 \leq F_{4}<0.7$ & $0.4 \leq F_{4}<0.5$ \\
\hline & Line layout & $60 \%$ & $0.85 \leq F_{5}$ & $0.75 \leq F_{5}<0.85$ & $0.65 \leq F_{5}<0.75$ & $0.55 \leq F_{5}<0.65$ \\
\hline & Site interference & $100 \%$ & $0.95 \leq F_{6}$ & $0.9 \leq F_{6}<0.95$ & $0.85 \leq F_{6}<0.90$ & $0.75 \leq F_{6}<0.85$ \\
\hline \multirow{2}{*}{ Geological condition } & $\begin{array}{l}\text { Tunnel face } \\
\text { information }\end{array}$ & 1 & $0.95 \leq F_{7}$ & $0.85 \leq F_{7}<0.95$ & $0.75 \leq F_{7}<0.85$ & $0.65 \leq F_{7}<0.75$ \\
\hline & $\begin{array}{l}\text { Overall tunnel } \\
\text { information }\end{array}$ & 1 & $0.75 \leq F_{8}$ & $0.5 \leq F_{8}<0.75$ & $0.25 \leq F_{8}<0.55$ & $0 \leq F_{8}<0.25$ \\
\hline Software processing & $\begin{array}{l}\text { Offset and } \\
\text { enhancement }\end{array}$ & 1 & $0.9 \leq F_{9}$ & $0.8 \leq F_{9}<0.9$ & $0.7 \leq F_{9}<0.8$ & $0.6 \leq F_{9}<0.7$ \\
\hline $\begin{array}{l}\text { Interpretation of image } \\
\text { data }\end{array}$ & 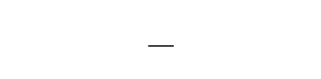 & 1 & $0.8 \leq F_{10}$ & $0.6 \leq F_{10}<0.8$ & $0.4 \leq F_{10}<0.6$ & $0.2 \leq F_{10}<0.4$ \\
\hline Prediction of distance & 一 & - & $F_{11} \leq 15 \mathrm{~m}$ & $15 \mathrm{~m}<F_{11} \leq 30 \mathrm{~m}$ & $30 \mathrm{~m}<F_{11} \leq 40 \mathrm{~m}$ & $40 \mathrm{~m}<F_{11}$ \\
\hline
\end{tabular}

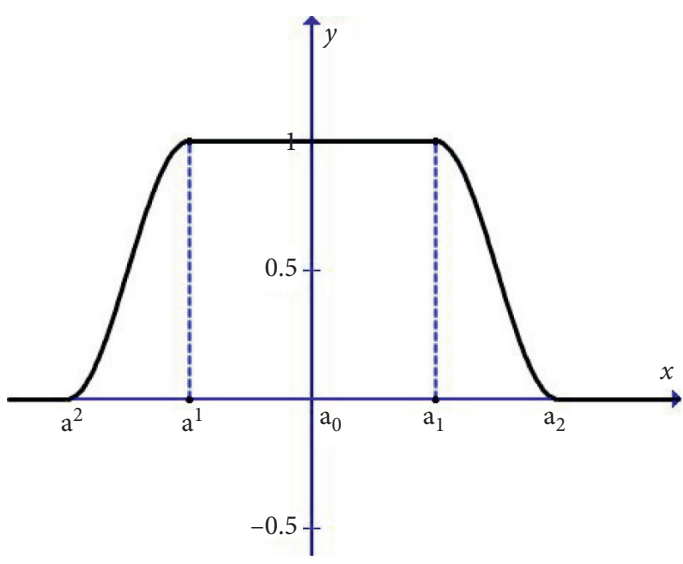

(a)

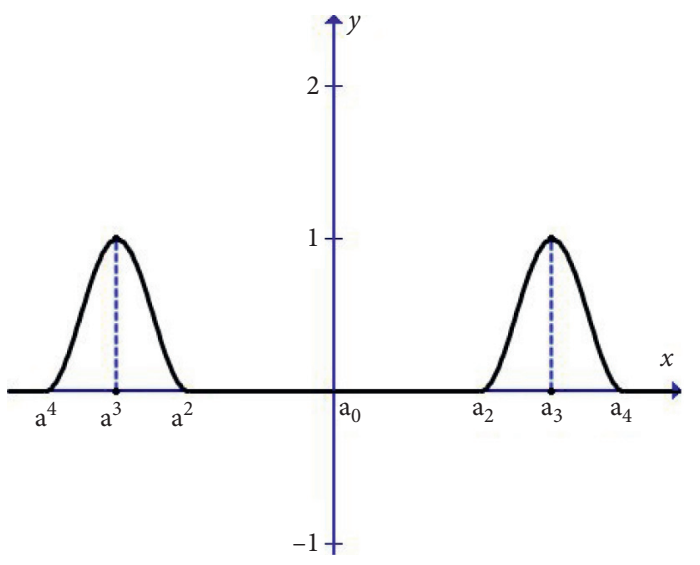

(c)

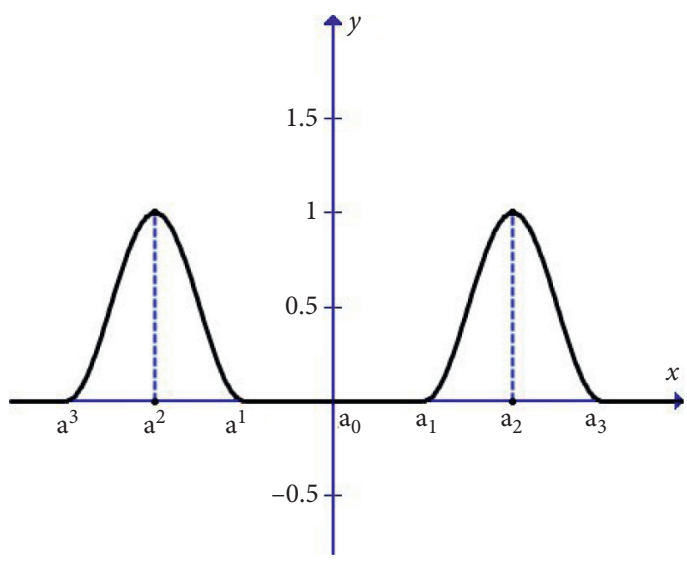

(b)

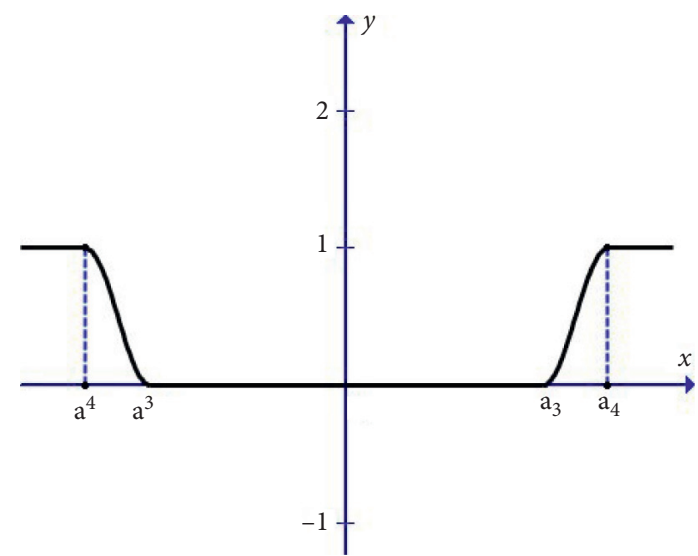

(d)

FIgure 3: Membership function (a) a-level, (b) b-level, (c) c-level, and (d) d-level. 
TABLE 2: Hierarchical evaluation model.

\begin{tabular}{|c|c|c|c|}
\hline $\begin{array}{l}\text { First level factor (fourth level } \\
\text { evaluation) }\end{array}$ & $\begin{array}{c}\text { Second level factor (third level } \\
\text { evaluation) }\end{array}$ & $\begin{array}{c}\text { Third level factor (second level } \\
\text { evaluation) }\end{array}$ & $\begin{array}{c}\text { Fourth level factor (first level } \\
\text { evaluation) }\end{array}$ \\
\hline \multirow{5}{*}{$\begin{array}{l}\text { Data acquisition and processing } \\
x_{1}\left(w_{1}\right)\end{array}$} & Raw data quality $x_{11}\left(w_{11}\right)$ & Parameter selection $x_{111}\left(w_{111}\right)$ & $\begin{array}{l}\text { Frequency selection } x_{1111}\left(w_{1111}\right) \\
\text { Time window selection } x_{1112} \\
\quad\left(w_{1112}\right) \\
\text { Antenna spacing selection } x_{1113} \\
\quad\left(w_{1113}\right) \\
\text { Measuring point distance } x_{1114} \\
\left(w_{1114}\right)\end{array}$ \\
\hline & & Signal coverage $x_{112}\left(w_{112}\right)$ & $\begin{array}{c}\text { Line layout } x_{1121}\left(w_{1121}\right) \\
\text { Site interference } x_{1122}\left(w_{1122}\right)\end{array}$ \\
\hline & Geological condition $x_{12}\left(w_{12}\right)$ & $\begin{array}{l}\text { Tunnel face information } x_{121} \\
\left(w_{121}\right)\end{array}$ & 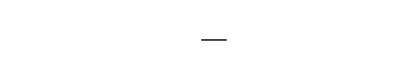 \\
\hline & 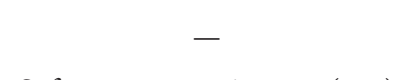 & $\begin{array}{l}\text { Overall tunnel information } x_{122} \\
\qquad\left(w_{122}\right)\end{array}$ & - \\
\hline & Software processing $x_{13}\left(w_{13}\right)$ & - & - \\
\hline $\begin{array}{l}\text { Interpretation of image data } x_{2} \\
\left(w_{2}\right)\end{array}$ & - & - & - \\
\hline Prediction of distance $x_{3}\left(w_{3}\right)$ & - & - & - \\
\hline
\end{tabular}

according to the membership function (Figure 3), and construct a fuzzy relationship matrix as follows [38]:

$$
\begin{aligned}
& R_{111}=\left[\mu_{R}\left(x_{1111}\right) \mu_{R}\left(x_{1112}\right) \mu_{R}\left(x_{1113}\right) \mu_{R}\left(x_{1114}\right)\right]^{T} \\
& =\left[\begin{array}{llll}
r_{1111 a} & r_{1111 b} & r_{1111 c} & r_{1111 d} \\
r_{1112 a} & r_{1112 b} & r_{1112 c} & r_{1112 d} \\
r_{1113 a} & r_{1113 b} & r_{1113 c} & r_{1113 d} \\
r_{1114 a} & r_{1114 b} & r_{1114 c} & r_{1114 d}
\end{array}\right], \\
& R_{112}=\left[\mu_{R}\left(x_{1121}\right) \mu_{R}\left(x_{1122}\right)\right]^{T} \\
& =\left[\begin{array}{llll}
r_{1121 a} & r_{1121 b} & r_{1121 c} & r_{1121 d} \\
r_{1122 a} & r_{1122 b} & r_{1122 c} & r_{1122 d}
\end{array}\right] \text {. }
\end{aligned}
$$

Combining the comprehensive weight $W_{111}=$ $\left[\begin{array}{llll}w_{1111} & w_{1112} & w_{1113} & w_{1114}\end{array}\right]$ and $W_{112}=\left[\begin{array}{ll}w_{1121} & w_{1122}\end{array}\right]$ can be calculated as

$$
\begin{aligned}
& \mu_{R}\left(x_{111}\right)=W_{111} \cdot R_{111}=\left[\begin{array}{llll}
r_{111 a} & r_{111 b} & r_{111 c} & r_{111 d}
\end{array}\right], \\
& \mu_{R}\left(x_{112}\right)=W_{112} \cdot R_{112}=\left[\begin{array}{llll}
r_{112 a} & r_{112 b} & r_{112 c} & r_{112 d}
\end{array}\right] .
\end{aligned}
$$

(2) Second level comprehensive evaluation matrix and mathematical model:

$$
\begin{aligned}
& R_{11}=\left[\begin{array}{ll}
\mu_{R}\left(x_{111}\right) & \mu_{R}\left(x_{112}\right)
\end{array}\right]^{T}=\left[\begin{array}{llll}
r_{111 a} & r_{111 b} & r_{11 c} & r_{111 d} \\
r_{112 a} & r_{112 b} & r_{112 c} & r_{112 d}
\end{array}\right], \\
& R_{12}=\left[\begin{array}{llll}
\mu_{R}\left(x_{121}\right) & \mu_{R}\left(x_{122}\right)
\end{array}\right]^{T}=\left[\begin{array}{llll}
r_{121 a} & r_{121 b} & r_{121 c} & r_{121 d} \\
r_{122 a} & r_{122 b} & r_{122 c} & r_{122 d}
\end{array}\right] .
\end{aligned}
$$

Combining the comprehensive weight $W_{11}=\left[\begin{array}{ll}w_{111} & w_{112}\end{array}\right]$ and $W_{12}=\left[\begin{array}{ll}w_{121} & w_{122}\end{array}\right]$ can be calculated as

$$
\begin{aligned}
& \mu_{R}\left(x_{11}\right)=W_{11} \cdot R_{11}, \\
& \mu_{R}\left(x_{12}\right)=W_{12} \cdot R_{12} .
\end{aligned}
$$

(3) Third level comprehensive evaluation matrix and mathematical model:

$$
\begin{aligned}
& R_{1}=\left[\begin{array}{lll}
\mu_{R}\left(x_{11}\right) & \mu_{R}\left(x_{12}\right) & \mu_{R}\left(x_{13}\right)
\end{array}\right]^{T} \\
& =\left[\begin{array}{llll}
r_{11 a} & r_{11 b} & r_{11 c} & r_{11 d} \\
r_{12 a} & r_{12 b} & r_{12 c} & r_{12 d} \\
r_{13 a} & r_{13 b} & r_{13 c} & r_{13 d}
\end{array}\right] \text {. }
\end{aligned}
$$

Combining the comprehensive weight $W_{1}=\left[\begin{array}{lll}w_{11} & w_{12} & w_{13}\end{array}\right]$ can be calculated as

$$
\mu_{R}\left(x_{1}\right)=W_{1} \cdot R_{1} \text {. }
$$

(4) Fourth level comprehensive evaluation matrix and mathematical model:

$$
R=\left[\begin{array}{lll}
\mu_{R}\left(x_{1}\right) & \mu_{R}\left(x_{2}\right) & \mu_{R}\left(x_{3}\right)
\end{array}\right]^{T}=\left[\begin{array}{llll}
r_{1 a} & r_{1 b} & r_{1 c} & r_{1 d} \\
r_{2 a} & r_{2 b} & r_{2 c} & r_{2 d} \\
r_{3 a} & r_{3 b} & r_{3 c} & r_{3 d}
\end{array}\right] \text {. }
$$

Combining the comprehensive weight $W=\left[\begin{array}{lll}w_{1} & w_{2} & w_{3}\end{array}\right]$ can be calculated as

$$
B=W \cdot R \text {. }
$$

Through the four-level evaluation, we finally get a fourdimensional vector $B=W \cdot R$, whose values are the 
membership degrees that are more accurate, accurate, relatively accurate, and inaccurate.

3.3.4. Fuzzy Model Identification. In this paper, the accuracy evaluation standards $a, b, c$, and $d$ established in advance are standard model libraries, and the four-dimensional vectors collected after comprehensive evaluation are the identification objects. The authors integrate the fuzzy comprehensive evaluation method using the membership degree established by the membership function for comprehensive evaluation into the AHP, and the fuzzy model is identified according to the maximum membership principle.

Suppose there is a standard model $A$ on the domain $x_{1}, x_{2}, \ldots, x_{n} \in U$, and there are $n$ objects to be identified. If there is $x_{k}$ that should be accepted first,

$$
\left.\underset{\sim}{A}\left(x_{k}\right)={\underset{i=1}{n}}_{\underset{\sim}{A}}^{A}\left(x_{i}\right)\right\} \text {. }
$$

\section{Engineering Application}

4.1. Engineering Situation. The no. 2 tunnel of Xiaobei Mountain was probably the most significant engineering feature of Jie (yang)-Hui (lai) Expressway project. The $1520 \mathrm{~m}$ long no. 2 tunnel of Xiaobei Mountain is located between the sections of $19.571 \mathrm{~km}$ and $21.091 \mathrm{~km}$ of Jie-Hui Expressway.

The maximum burial depth of no. 2 tunnel of Xiaobei Mountain is $212 \mathrm{~m}$, so the tunnel is classified to be a longdeep tunnel. The tunnel site area is mainly granite, and the aquifer is mainly the pores of the quaternary loose layer and the weathering fissures of the middle to slightly weathered rocks. The development of local fractures supplies physical space for the groundwater storage.

4.2. GPR Prediction. The GPR detection image of $\mathrm{K} 19+715-\mathrm{K} 19+745$ is shown in Figure 4, and the brief conclusions of advanced geological prediction are represented below:

(1) $\mathrm{K} 19+715-\mathrm{K} 19+720$ : it is speculated that the surrounding rock of this section is strongly weathered granite, with poor stability, developed joint fissures, and water bearing, which is prone to water seepage and block falling.

(2) $\mathrm{K} 19+720-\mathrm{K} 19+730$ : it is speculated that the integrity of the surrounding rock in this section is general and the fissures are relatively developed, mainly containing water. The rock mass is of massive or layered structure.

(3) $\mathrm{K} 19+730-\mathrm{K} 19+745$ : it is speculated that the surrounding rock condition in this section is better and the stability is better.

4.3. Evaluation Factor Value. Regarding the standard value, there is no established corresponding standard for the accuracy evaluation of GPR. The authors combined the large amount of detection experience of forecasters and the investigation and evaluation of relevant experts to obtain the optimal value of each factor in the common advance prediction, which is standard value. According to the degree of deviation from the standard value, we use more accurate, accurate, relatively accurate, and inaccurate for demarcation.

The actual value of some evaluation factors is closely related to the situation of the tunnel face $(\mathrm{K} 19+715)$, and a brief description is as follows:

(1) Measuring point distance: The actual value is calculated according to the walking speed, the lateral length of the tunnel face, the round-trip time of the measuring line, and the frequency of the instrument operator's tapping signal. The average value is taken.

(2) Site interference: There are many interference factors. In this example, the block of the trolley makes a small part of the antenna of the survey line not close to the tunnel face. According to the length loss of the projected tunnel face, the value is $13 \%$, and the actual value is $87 \%$.

(3) Tunnel face information: When the tunnel face can be observed at close range and a relatively complete geological sketch can be completed, this value can be above 0.8 , which is 0.8 in this case.

(4) Line layout: The final coverage rate is calculated by dividing the area covered by the antenna during walking by the total area of the tunnel face, which is about $50 \%$.

(5) Software processing and interpretation of image data: Considering that several geological predictions have been carried out in this project, and combined with the results of the questionnaire, the technical staff's software processing and interpretation level is considered acceptable, and the value is 0.8 .

The remaining evaluation factors are related to the overall situation of the tunnel and the actual needs of the technicians and are usually determined as fixed values. The final value of the evaluation factor is shown in Table 3.

4.4. Determination of Comprehensive Weights. According to the results of the questionnaire survey, the feature weights are determined to form a judgment matrix. In order to improve the calculation accuracy and efficiency, Matlab is used to obtain the eigenvalues and eigenvectors of the judgment matrix. The calculation results of the evaluation factors at all levels are as follows.

(1) The first level evaluation factors include "parameter selection" (Table 4) and "signal coverage" (Table 5).

(2) The second level evaluation factors include "raw data quality" (Table 6) and "geological condition" (Table 7).

(3) The third level evaluation factors include "data acquisition and processing" (Table 8).

(4) The final calculation results of the evaluation factor at the fourth level is shown in Table 9. 


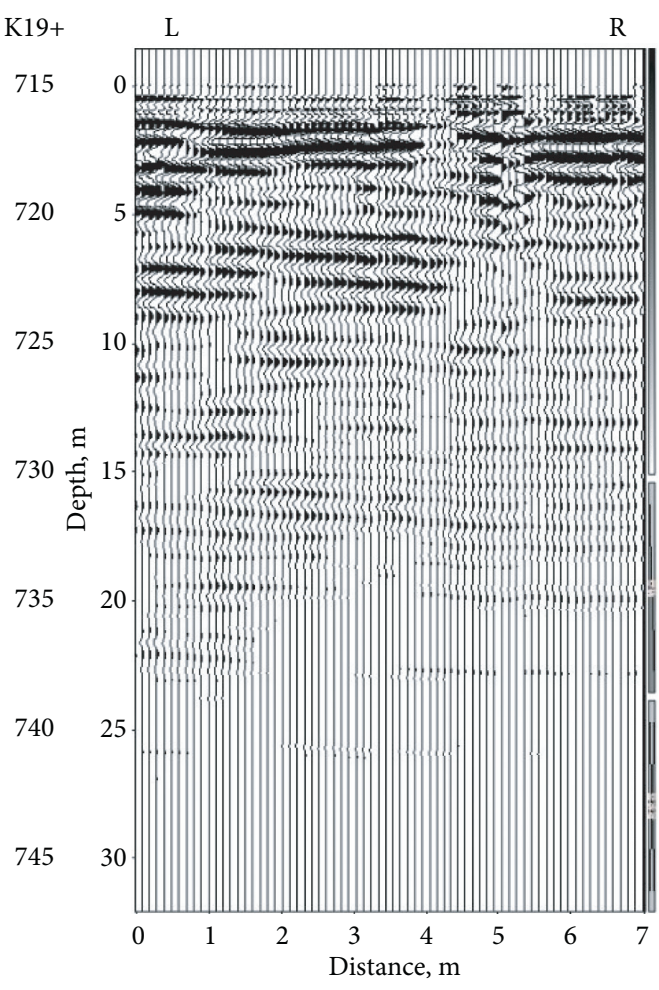

(a)

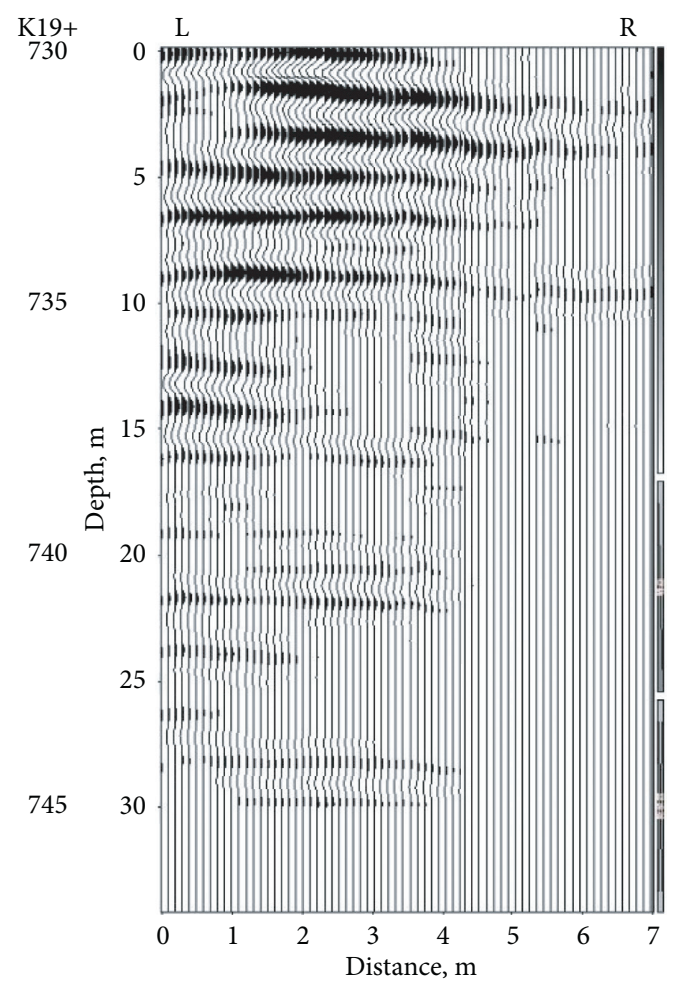

(b)

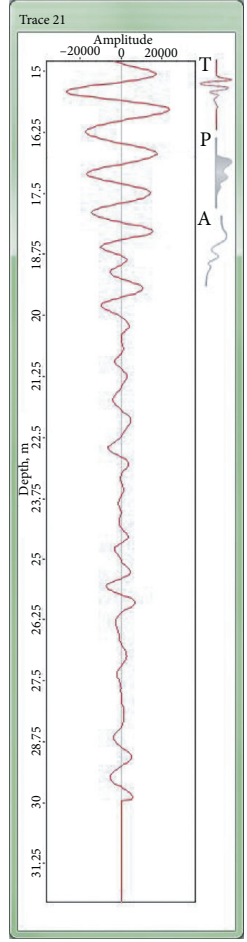

(c)

FIgURE 4: GPR detection image of K19+715-K19+745. (a) Background removal. (b) Gain 35 dB. (c) Trace21.

TABLE 3: Grading and value of evaluation factors.

\begin{tabular}{|c|c|c|c|c|c|c|c|}
\hline Factor & $\begin{array}{l}\text { Actual } \\
\text { value }\end{array}$ & $\begin{array}{l}\text { Standard } \\
\text { value }\end{array}$ & $\begin{array}{l}\text { Relative } \\
\text { value }\end{array}$ & $\begin{array}{c}\text { More } \\
\text { accurate }\end{array}$ & Accurate & $\begin{array}{l}\text { Relatively } \\
\text { accurate }\end{array}$ & Inaccurate \\
\hline Frequency selection & $100 \mathrm{MHz}$ & $100 \mathrm{MHz}$ & 1 & $\begin{array}{r}85-115 \\
0.85 \leq F_{1}\end{array}$ & $\begin{array}{c}75-85 \\
115-125 \\
0.7 \leq F_{1}<0.85\end{array}$ & $\begin{array}{c}65-75 \\
125-135 \\
0.65 \leq F_{1}<0.75\end{array}$ & $\begin{array}{c}<65 \\
>135 \\
0.4 \leq F_{1}<0.65\end{array}$ \\
\hline Time window selection & $500 \mathrm{~ns}$ & $500 \mathrm{~ns}$ & 1 & $\begin{array}{l}450-500 \\
0.9 \leq F_{2}\end{array}$ & $\begin{array}{c}400-450 \\
550-600 \\
0.8 \leq F_{2}<0.9\end{array}$ & $\begin{array}{c}350-400 \\
600-650 \\
0.7 \leq F_{2}<0.8\end{array}$ & $\begin{aligned} & <350 \\
& >650 \\
0.6 & \leq F_{2}<0.7\end{aligned}$ \\
\hline $\begin{array}{l}\text { Antenna spacing } \\
\text { selection }\end{array}$ & $1.5 \mathrm{~m}$ & $1.8 \mathrm{~m}$ & 0.6 & $\begin{array}{c}1.8-2.1 \\
2.1-2.2 \\
0.95 \leq F_{3}\end{array}$ & $\begin{array}{c}1.4-1.8 \\
2.2-2.6 \\
0.85 \leq F_{3}<0.95\end{array}$ & $\begin{array}{c}1.0-1.4 \\
2.6-3.0 \\
0.75 \leq F_{3}<0.85\end{array}$ & $\begin{aligned} & <1.0 \\
& >3.0 \\
0.65 & \leq F_{3}<0.75\end{aligned}$ \\
\hline $\begin{array}{l}\text { Measuring point } \\
\text { distance }\end{array}$ & $0.08 \mathrm{~m}$ & $0.1 \mathrm{~m}$ & 0.8 & $\begin{array}{c}0.095-0.105 \\
0.9 \leq F_{4}\end{array}$ & $\begin{array}{c}0.085-0.095 \\
0.105-0.115 \\
0.7 \leq F_{4}<0.9\end{array}$ & $\begin{array}{c}0.075-0.085 \\
0.115-0.125 \\
0.5 \leq F_{4}<0.7\end{array}$ & $\begin{array}{c}<0.075 \\
>0.125 \\
0.4 \leq F_{4}<0.5\end{array}$ \\
\hline Line layout & $50 \%$ & $60 \%$ & 0.68 & $\begin{array}{c}>51 \% \\
0.85 \leq F_{5}\end{array}$ & $\begin{array}{c}45 \%-51 \% \\
0.75 \leq F_{5}<0.85\end{array}$ & $\begin{array}{c}39 \%-45 \% \\
0.65 \leq F_{5}<0.75\end{array}$ & $\begin{array}{c}<39 \% \\
0.55 \leq F 5<0.65\end{array}$ \\
\hline Site interference & $87 \%$ & $100 \%$ & 0.9 & $\begin{array}{c}95 \% \\
0.95 \leq F_{6}\end{array}$ & $\begin{array}{c}90 \%-95 \% \\
0.9 \leq F_{6}<0.95\end{array}$ & $\begin{array}{c}85 \%-90 \% \\
0.85 \leq F_{6}<0.90\end{array}$ & $\begin{aligned} & <85 \% \\
0.75 & \leq F 6<0.85\end{aligned}$ \\
\hline $\begin{array}{l}\text { Tunnel face } \\
\text { information }\end{array}$ & 0.8 & 1 & 08 & $\begin{array}{c}0.95-1 \\
10.95 \leq F_{7}\end{array}$ & $\begin{array}{c}0.85-0.95 \\
0.85 \leq F_{7}<0.95\end{array}$ & $\begin{array}{c}0.75-0.85 \\
0.75 \leq F_{7}<0.85\end{array}$ & $\begin{aligned} & <0.75 \\
0.65 & \leq F 7<0.75\end{aligned}$ \\
\hline $\begin{array}{l}\text { Overall tunnel } \\
\text { information }\end{array}$ & 0.6 & 1 & 0.5 & $\begin{array}{c}0.75-1 \\
0.75 \leq F_{8}\end{array}$ & $\begin{array}{c}0.5-0.75 \\
0.5 \leq F_{8}<0.75\end{array}$ & $\begin{array}{c}0.25-0.5 \\
0.25 \leq F_{8}<0.55\end{array}$ & $\begin{array}{c}0-0.25 \\
0 \leq F 8<0.25\end{array}$ \\
\hline Software processing & 0.8 & 1 & 0.9 & $\begin{array}{c}0.9-1 \\
0.9 \leq F_{9}\end{array}$ & $\begin{array}{c}0.8-0.9 \\
0.8 \leq F_{9}<0.9\end{array}$ & $\begin{array}{c}0.7-0.8 \\
0.7 \leq F_{9}<0.8\end{array}$ & $\begin{array}{c}<0.7 \\
0.6 \leq F_{9}<0.7\end{array}$ \\
\hline $\begin{array}{l}\text { Interpretation of } \\
\text { image data }\end{array}$ & 0.8 & 1 & 0.8 & $\begin{array}{c}0.8-1 \\
0.8 \leq F_{10}\end{array}$ & $\begin{array}{c}0.6-0.8 \\
0.6 \leq F_{10}<0.8\end{array}$ & $\begin{array}{c}0.4-0.6 \\
0.4 \leq F_{10}<0.6\end{array}$ & $\begin{array}{c}<0.4 \\
0.2 \leq F_{10}<0.4\end{array}$ \\
\hline Prediction of distance & $30 \mathrm{~m}$ & - & - & $0-15 \mathrm{~m}$ & $15-30 \mathrm{~m}$ & $30-40 \mathrm{~m}$ & $>40 \mathrm{~m}$ \\
\hline
\end{tabular}


TABLE 4: The importance comparison and weight of each factor of "parameter selection."

\begin{tabular}{lcccc}
\hline Evaluation factor & Frequency selection & Time window selection & Antenna spacing selection & Measuring point distance \\
\hline Frequency selection & 1 & $3 / 2$ & 1 & $4 / 3$ \\
Time window selection & $2 / 3$ & 1 & $2 / 3$ & $2 / 3$ \\
Antenna spacing selection & 1 & $3 / 2$ & 1 & 1 \\
Measuring point distance & $3 / 4$ & $3 / 2$ & 1 & 1 \\
Feature weight & $\quad \alpha=\left[\begin{array}{llll}0.293 & 0.181 & 0.272 & 0.254\end{array}\right]$ \\
Numerical weight & $\beta=\left[\begin{array}{llll}0.299 & 0.265 & 0.198 & 0.238\end{array}\right]$ \\
Comprehensive weight & \multicolumn{1}{l}{$\left.\begin{array}{llll}0.351 & 0.192 & 0.216 & 0.242\end{array}\right]$} \\
\hline
\end{tabular}

TABLE 5: The importance comparison and weight of each factor of "signal coverage."

\begin{tabular}{lcc}
\hline Evaluation factor & Line layout & Site interference \\
\hline Line layout & 1 & 2 \\
Site interference & $1 / 2$ & 1 \\
Feature weight & $\alpha=\left[\begin{array}{ll}0.667 & 0.333\end{array}\right]$ \\
Numerical weight & $\beta=\left[\begin{array}{ll}0.541 & 0.459\end{array}\right]$ \\
Comprehensive weight & $W_{112}=\left[\begin{array}{ll}0.702 & 0.298\end{array}\right]$ \\
\hline
\end{tabular}

TABLE 6: The importance comparison and weight of each factor of "raw data quality."

\begin{tabular}{lcc}
\hline Evaluation factor & Parameter selection & Signal coverage \\
\hline Parameter selection & 1 & 3 \\
Signal coverage & $1 / 3$ & 1 \\
Feature weight & $\alpha=\left[\begin{array}{ll}0.75 & 0.25\end{array}\right]$ \\
Comprehensive weight & $W_{11}=\left[\begin{array}{ll}0.75 & 0.25\end{array}\right]$ \\
\hline
\end{tabular}

TABLE 7: The importance comparison and weight of each factor of "geological condition."

\begin{tabular}{lcc}
\hline Evaluation factor & Parameter selection & Signal coverage \\
\hline Tunnel face information & 1 & 6 \\
Overall tunnel information & $1 / 6$ & 1 \\
Feature weight & $\alpha=\left[\begin{array}{ll}0.857 & 0.143\end{array}\right]$ \\
Comprehensive weight & $W_{12}=\left[\begin{array}{ll}0.857 & 0.143\end{array}\right]$ \\
\hline
\end{tabular}

4.5. Results of Improved AHP Method. According to the improved AHP evaluation model, the fuzzy matrix is obtained:

$$
\begin{aligned}
R & =\left[\mu_{R}\left(x_{1}\right) \mu_{R}\left(x_{2}\right) \mu_{R}\left(x_{3}\right)\right]^{T}=\left[\begin{array}{llll}
r_{1 a} & r_{1 b} & r_{1 c} & r_{1 d} \\
r_{2 a} & r_{2 b} & r_{2 c} & r_{2 d} \\
r_{3 a} & r_{3 b} & r_{3 c} & r_{3 d}
\end{array}\right] \\
& =\left[\begin{array}{cccc}
0.424 & 0.440 & 0.136 & 0 \\
0.5 & 0.5 & 0 & 0 \\
0 & 1 & 0 & 0
\end{array}\right] .
\end{aligned}
$$

According to the fuzzy matrix $R$, substituting the fourth level evaluation weight $W$, the fuzzy evaluation matrix $B$ obtained by this advanced geological prediction accuracy evaluation is

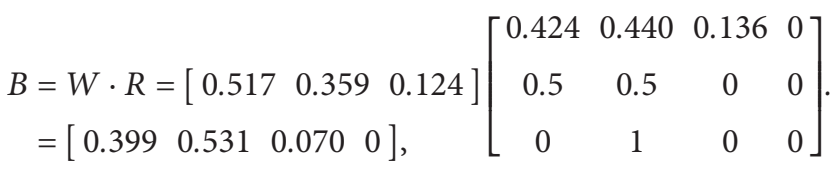

According to the principle of maximum membership $A=\{$ more accurate, accurate, relatively accurate, inaccurate $\}$, $\tilde{x}_{2}=0.531$ satisfies

$$
\underset{\sim}{A}\left(x_{2}\right)=\underset{i=1}{\stackrel{4}{\bigvee}}\left\{\underset{\sim}{A}\left(x_{i}\right)\right\} .
$$

That is, the final four-dimensional vector has the highest degree of membership to the b-level (0.531), so the final evaluation result of accuracy is accurate.

4.6. Excavation Verification. When the tunnel excavation reaches $\mathrm{K} 19+717$, the fissure water appears in the tunnel face, and the surrounding rock is broken (Figure 5).

When the tunnel excavation reaches $\mathrm{K} 19+728$, the stability of the tunnel face is improved, and the amount of water is reduced (Figure 6), which is slightly different from the prediction result.

When the tunnel excavation reaches $\mathrm{K} 19+742$, the stability of the rock mass is poor, mainly due to strong weathering, and the surface of the rock mass is partially infiltrated (Figure 7).

In this section, three characteristic pile sections are selected to compare the actual excavation results with the prediction results. It can be seen that most of the prediction results are relatively accurate. Most of the unshown stake sections are similar to the predicted results. It can be said that the advanced prediction results for this $30 \mathrm{~m}$ section is accurate and can be used. At the same time, it can be noticed that one characteristic station section is misjudged. When the unfavorable geological mixing occurs, such as obvious fracture development and disordered water content, the overall waveform can often be judged as a water-bearing fracture zone. Only by carefully observing the characteristics of each waveform can the size of water content be clearly confirmed, which makes the work volume greatly changed, and it is difficult to realize in practice.

In general, in the process of accuracy evaluation of advanced geological prediction, the factors involved are complicated, and many factors have previously been restricted and correlated with each other. Most of the influencing factors cannot be quantitatively analyzed, but they 
TABLE 8: The importance comparison and weight of each factor of "data acquisition and processing."

\begin{tabular}{lccc}
\hline Evaluation factor & Raw data quality & Geological condition & Software processing \\
\hline Raw data quality & 1 & 6 & 4 \\
Geological condition & $1 / 6$ & 1 & $1 / 2$ \\
Software processing & $1 / 4$ & 2 & 1 \\
Feature weight & & $\alpha=\left[\begin{array}{llll}0.701 & 0.106 & 0.193\end{array}\right]$ & \\
Comprehensive weight & & $W=\left[\begin{array}{lll}0.701 & 0.106 & 0.193\end{array}\right]$ & \\
\hline
\end{tabular}

TABLE 9: The importance comparison and weight of each factor of "accuracy of advanced geological prediction of GPR."

\begin{tabular}{lccc}
\hline Evaluation factor & Data acquisition and processing & Interpretation of image data & Prediction of distance \\
\hline Data acquisition and processing & 1 & $3 / 2$ & 4 \\
Interpretation of image data & $2 / 3$ & 1 & 3 \\
Prediction of distance & $1 / 4$ & $\alpha=\left[\begin{array}{ccc}0.517 & 0.359 & 0.124\end{array}\right]$ & 1 \\
Feature weight & & $W=\left[\begin{array}{lll}0.517 & 0.359 & 0.124\end{array}\right]$ \\
Comprehensive weight & & & \\
\hline
\end{tabular}

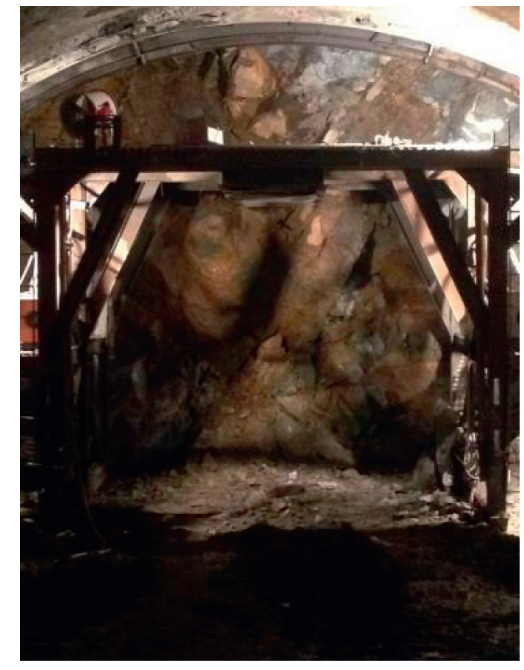

Figure 5: Tunnel face at K19+717.

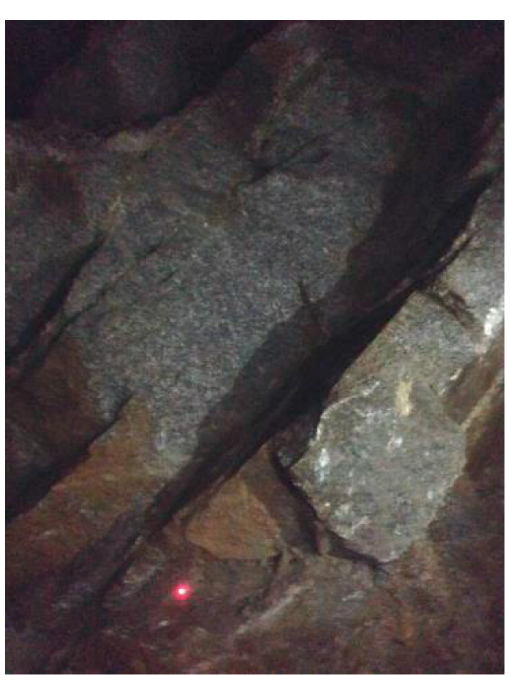

Figure 6: Tunnel face at K19+728.

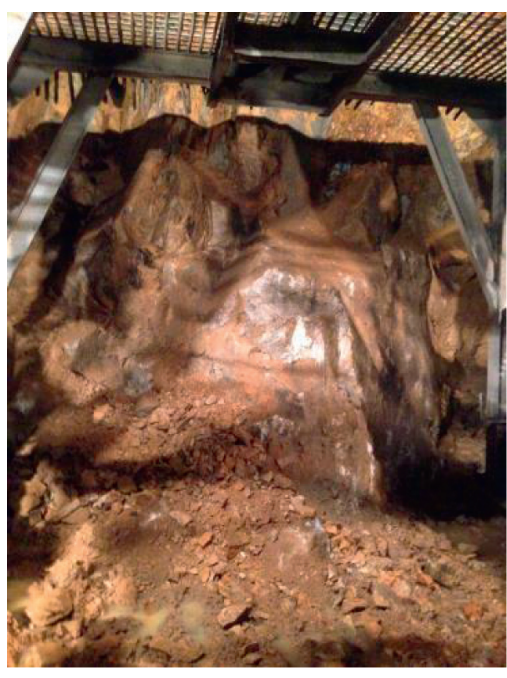

FIgURE 7: Tunnel face at K19+742.

are indispensable evaluation factors, so they can only be judged by the concept of fuzzy mathematics. And it is impossible to establish an accurate mathematical model to solve the interaction among the change of evaluation factors, the accuracy of prediction results, and the actual excavation. Therefore, this paper uses the evaluation model established by the improved analytic hierarchy process to combine the three as closely as possible and explore the reasonable and scientific relationship between the three.

In summary, according to the analysis results of engineering application examples, it can be known that this improved AHP method is feasible to evaluate the accuracy of advanced geological prediction.

\section{Conclusion}

Based on the study above, some important conclusions can be summarized. 
(1) Combined with engineering experience and relevant cases, the factors affecting the accuracy of advanced geological prediction were summarized, and 11 main factors were selected. These factors are classified, graded, and valued, and a hierarchical structure system is constructed.

(2) The method of fuzzy comprehensive evaluation using membership degree to make the final evaluation is integrated into the AHP, and a grading evaluation model of GPR advanced prediction accuracy is established. The model is used to evaluate the advanced geological prediction of the no. 2 tunnel of Xiaobei Mountain. The actual excavation exposure shows that the advanced geological prediction is accurate, which is consistent with the evaluation result.

(3) The improved AHP-GPR method is based on the results of GPR. This approach has two advantages. One is the easy accessibility of the data of the main factor and the other is the applicability of the method. In addition, the results of the assessment are closely related with the detection accuracy of GPR. Improving the interpretation of the GPR can effectively improve the accuracy of the evaluation results. This method can also be applied to other advanced detection techniques based on seismic waves (e.g., TGP and TSP).

\section{Data Availability}

The data used to support the findings of this study are available from the corresponding author upon request.

\section{Conflicts of Interest}

The authors declare that they have no conflicts of interest.

\section{Acknowledgments}

The research was supported by Guangdong Provincial Department of Transportation Science and Technology Project (no. 2015-02-002).

\section{References}

[1] Y.-Z. Ye, "Prediction and construction of bad geological hazards in Zhongnanshan extra-long highway tunnel," WestChina Exploration Engineering, vol. 14, no. 5, pp. 97-98, 2002.

[2] B.-C. Wang, "Application of GPR advanced prediction technology in tunnel construction," East China Science \& Technology, vol. 4, pp. 131-132, 2015.

[3] S. Chen, L.-M. Zhou, and S.-X. Luo, "Forward simulation of GPR signals and application examples for tunnel's advance forecast," Journal of Yangtze River Scientific Research Institute, vol. 32, no. 9, pp. 128-133, 2015.

[4] Y.-F. Xue, J.-S. He, and Y.-S. Guo, "Advance geological prediction system research used in deeply buried tunnel project of south-to-north transfer water," Progress in Geophysics, vol. 21, no. 3, pp. 993-997, 2006.
[5] M. Wang, "Research on influencing factors of GPR's detection effectiveness," Radar Science and Technology, vol. 5, no. 2, pp. 86-90, 2007.

[6] D.-X. Li, Ground Penetrating Radar Method and Application, Geological Press, Beijing, China, 1994.

[7] K. Wang and Z.-G. Liu, "GPR technology and its application in military geophysics," in The 3rd National Security Geophysical Symposium, Xi'an, China, 2007.

[8] F. Abujarad, G. Nadim, and A. Omar, "Combining wavelet packets with higher-order-statistic for GPR detection of nonmetallic anti-personnel land mines," in Proceedings of the Image \& Signal Processing for Remote Sensing XI, p. 5982A, Bruges, Belgium, 2005.

[9] A. P. Ermakov and A. V. Starovoitov, "The use of the ground penetrating radar (GPR) method in engineering-geological studies for the assessment of geological-cryological conditions," Moscow University Geology Bulletin, vol. 11, no. 11, pp. 211-221, 1970.

[10] D. Domenico, A. Teramo, and D. Campo, "GPR surveys for the characterization of foundation plinths within a seismic vulnerability analysis," Journal of Geophysics \& Engineering, vol. 10, no. 3, Article ID 034007, 2013.

[11] N. Pinel, C. L. Bastard, C. Bourlier et al., "Asymptotic modeling of coherent scattering from random rough layers: application to road survey by GPR at Nadir," International Journal of Antennas \& Propagation, vol. 2012, no. 5, pp. 1497-1500, Article ID 874840, 2012.

[12] W.-F. Zhan, T.-H. Xi, and Q. Wang, "Application of ground penetrating radar (GPR) on foundation cavity detection," Coal Geology of China, vol. 11, pp. 70-73, 2015.

[13] H. Li, Y.-J. Jiao, and J.-B. Yang, "A tentative discussion on the development and application of GPR technology in China," Computing Techniques for Geophysical and Geochemical Exploration, vol. 32, no. 3, pp. 292-299, 2010.

[14] S.-P. Peng, F. Yang, and H.-Q. Su, "Development and application of high-effective sampling ground penetrating radar," Geology and Prospecting, vol. 38, no. 5, pp. 63-66, 2002.

[15] M.-D. Wang, "Application of the ground penetrating radar in pipeline detection," Chinese Journal of Engineering Geophysics, vol. 6, no. S1, pp. 65-68, 2009.

[16] X.-L. Fu, K.-D. Li, and H.-F Huang, "Application and practice of GPR in archaeological exploration," in Proceedings of the 20th Anniversary Celebration and Academic Annual Meeting of Shanghai Geophysical Society.

[17] S.-K. Deng, B. Mei, and C.-B. Hu, "Ground penetrating radar detection of underground unknown mining cavities in the open-pit at the Zijinshan Au-Cu deposit," Mineral Resources and Geology, vol. 22, no. 3, pp. 255-260, 2008.

[18] M. D’Esposito, G. K. Aguirre, E. Zarahn et al., “Ground penetrating radar imaging of a collapsed paleocave system in the Ellenburger dolomite, central Texas," Journal of Applied Geophysics, vol. 39, no. 1, pp. 1-10, 1998.

[19] S. Carlsten, S. Johansson, and A. Wörman, "Radar techniques for indicating internal erosion in embankment dams," Journal of Applied Geophysics, vol. 33, no. 1-3, pp. 143-156, 1995.

[20] B.-B. Guo, W.-H. Zhao, H.-C. Wang et al., "Geological radar survey and stability analysis of rock slope in Qianling Mountain," Journal of Geomechanics, vol. 19, no. 1, pp. 104112, 2013.

[21] H.-S. Zhang, Z.-S. Lan, Y.-S Zhang et al., “The application of geological radar to the investigation of Shanzhouba karst collapse in Ruijin," Geophysical and Geochemical Exploration, vol. 24, no. 6, pp. 459-463, 2000. 
[22] A. Benedetto, "Prediction of structural damages of road pavement using GPR," in Proceedings of the 2007 4th International Workshop on Advanced Ground Penetrating Radar, pp. 290-294, IEEE, Aula Magna Partenope, Italy, June 2007.

[23] G. N. Tsokas, J.-Ho Kim, P. L. Tsourlo et al., "Investigating behind the lining of the tunnel of Eupalinus in Samos (Greece) using ERT and GPR," Near Surface Geophysics, vol. 19, no. 1, pp. 1-10, 1988.

[24] J.-Z Deng, M. Han, and Q.-C. Liu, "The application of groundpenetrating radar to karst detection," Geophysical and Geochemical Exploration, vol. 6, pp. 474-476, 2001.

[25] D.-W. Liu, G.-Y. Xu, R.-D. Huang et al., "Ground penetrating radar survey in highway construction," Journal of Highway and Transportation Research and Development, vol. 21, no. 5, pp. 33-35, 2004.

[26] C.-Z. Cheng and P.-F. Li, "Application of GPR in the detection of hidden karst at the bottom of subway foundation pit," Geotechnical Engineering Technique, vol. 26, no. 6, pp. 321-323, 2012.

[27] B. Li, "The application of geological radar in advanced geological forecast of subway tunnel," Shanxi Architecture, vol. 40, no. 4, pp. 173-174, 2014.

[28] T. Ren, Q.-H. Wei, D.-Y. Jiang et al., “The measures to improve the geological advanced prediction system of tunnel in seismic area," Chinese Journal of Underground Space and Engineering, vol. 12, no. 3, pp. 819-824, 2016.

[29] T.-B. Li, L.-B. Meng, J. Zhu et al., "Comprehensive analysis method for advance forecast of geology in tunnels," Chinese Journal of Rock Mechanics and Engineering, vol. 28, no. 12, pp. 2429-2436, 2009.

[30] Y.-H. Ge, S.-C. Li, Q.-S. Zhang et al., "Comprehensive geological prediction based on risk evaluation during tunneling in karst area," Chinese Journal of Geotechnical Engineering, vol. 32, no. 7, pp. 1124-1130, 2010.

[31] Y. Lu, X.-W. Hu, L.-B. Guo et al., "Application of fuzzy comprehensive method to tunnel geological prediction," Safety and Environmental Engineering, vol. 17, no. 1, pp. 116-119, 2010.

[32] Z.-L. Li, X.-H. Wang, and L.-Z. Xie, "Risk evaluation and comprehensive geological prediction based on fuzzy wavelet neural network during tunneling in karst area," Geoscience, vol. 27, no. 3, pp. 719-726, 2013.

[33] S.-S. Shi, S.-C. Li, L.-P. Li et al., "Advance optimized classification and application of surrounding rock based on fuzzy analytic hierarchy process and Tunnel Seismic Prediction," Automation in Construction, vol. 37, pp. 217-222, 2014.

[34] F.-M. Wang, The FDTD Modeling and Simulation of GPR, Nanchang University, Nanchang, China, 2010.

[35] T. L. Saaty and L. T. Tran, "On the invalidity of fuzzifying numerical judgments in the Analytic Hierarchy Process," Mathematical and Computer Modelling, vol. 46, no. 7-8, pp. 962-975, 2007.

[36] T. L. Saaty, "Exploring the interface between the hierarchies, multiple objectives and the fuzzy sets," Fuzzy Sets and Systems, vol. 1, pp. 57-68, 1978.

[37] T. L. Saaty, The Analytic Hierarchy Process: Planning, Priority Setting, Resource Allocation, McGraw-Hill, New York, NY, USA, 1980.

[38] S.-B. Xu, Practical Decision Method: Analytic Hierarchy Process Principle, Tianjin University Press, Tianjin, China, 1988.

[39] J. N. Mordeson, Fuzzy Mathematics, Physica-Verlag, New York, NY, USA, 2001. 